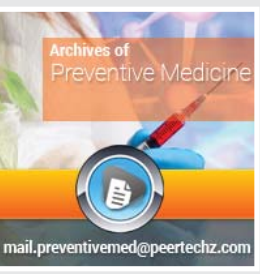

\title{
Archives of Preventive Medicine
}

Gülnaz Karatay*, Yeliz Akkuş², Barış Öztürk ${ }^{3}$ and Barlas Sülü̈ ${ }^{4}$

'Tunceli University, Health High School, Tunceli, Turkey

${ }^{2}$ Kafkas University, Health High School, Kars, Turkey ${ }^{3}$ University of Biruni, Depertmant of Nutrition and Dietetics, Istanbul, Turkey

${ }^{4}$ Kafkas University, Medical Faculty, Department of General Surgery, Kars, Turkey

Dates: Received: 02 December, 2016; Accepted: 29 December, 2016; Published: 30 December, 2016

*Corresponding author: Gülnaz Karatay, PhD, RN, Associate Professor, Tunceli University, Health High School, Tunceli, Turkey -62000, GSM: 05067433444; Tel: 042821317 94; Fax: 0-428-213 1861; E-mail: gkaratay@gmail.com

Keywords: Diabetes; Education; Patient; Home visit; Health team

https://www.peertechz.com

\section{Research Article \\ The Effectiveness of a Home-Based Diabetes Management Program on Diabetes Control}

\section{Abstract}

Background: Diabetes is a lifelong disease and reduces the victim's lifespan and quality of life. Diabetes management is a continuing life-long endeavor requiring cognitive, attitudinal and behavioral changes.

The purpose of the study: To evaluate the effectiveness of home based diabetes management programme on diabetes control conducted by health team.

Methods: This study which was designed as a one-group pretest-posttest pattern. Home visits were carried out once a week for nine weeks for 52 patients. The obtained data were evaluated by using percentages, t-test and the McNemar significance test.

Results: At the completion of the intervention, life-style changes, such as the frequency of controlling blood glucose, glycemic control, exercise, and increasing vegetable and fruit consumption all produced changes which proved statistically significant and positive. Similarly, in comparison to before the intervention, the results after completion of the intervention showed that the values of patients' weight $(86.28 \pm 13.50,80.40 \pm 23: 13)$, systolic blood pressure $(139.75 \pm 17.53,135.31 \pm 17.91)$, and postprandial blood glucose $(265.63 \pm 128.63,215.48 \pm 69.71)$ had all statistically and significantly decreased $(p<0.05)$.

Conclusion: This team study created a positive change in terms of managing patients' diabetes.

\section{Abbreviations}

DM: Diabetes Mellitus; BMI: Body Mass Index; COPD: Chronic Obstructive Pulmoner Disease; ADA: American Diabetes Association; IDF: International Diabetes Federation; TURDEP: General Outcomes of Turkey Diabetes Epidemiology Study

\section{Introduction}

Diabetes is a very common disease associated with the deterioration in carbonhydrate, protein and lipid metabolism. Those affected by diabetes can also incur a high financial burden for treatment and management of the disease [1]. Throughout the world it has been estimated that the prevalence of Diabetes Mellitus (DM) has been gradually increasing due to factors such as sedentary lifestyle and obesity, and it will affect approximately $5.4 \%$ of the world's adult population by the year 2025 [2]. Populations of developing countries such as Turkey are at a higher risk for developing DM [3]. According to data of TURDEP-II study the prevalance of Type 2 diabetes it is found as $13.7 \%$ on Turkish adult population. In the same study, the maximum prevalance of regional diabetes found in the East Anatolian Province of Turkey as $18.2 \%$ [4].

Because DM is a lifelong disease and causes significant complications, it substantially reduces the victim's lifespan and quality of life $[5,6]$. In order to prevent complications such as retinopathy, nephropathy, neuropathy, end-stage renal disease and non-traumatic lower extremity amputations associated with this disease, patients must change their way of life and maintain those changes [6-8]. According to IDF (International Diabetes Federation) self-management and permanent support are the two important components which are effecting metabolic and pyschological consequences [9]. Hence it is inevitable to improve sufficiency of disease management.

In order to effective self-management, diabetes patients need to acquire enough knowledge about their disease, accept their disease and develop a positive attitude towards controlling the disease [10]. Developing a positive attitude towards diabetes can be facilitated with the help of a professional team who offer 
such support to patients. Furthermore, the guidebook of the Diabetes Institute emphasizes the importance of primary care and caregivers [11].

Coping with the effects of DM requires the patients to develop specific cognitive, behavioral and social skills in order to be able to successfully manage their disease throughout their entire life. However, even though available studies indicate that patients find lifestyle and other disease management skills useful, they find it quite difficult to actually make real changes in their lifestyle [12]. For example, the Kartal et al., study (2008) determined that although the majority of the patients stated that they measure their blood glucose levels, $59.8 \%$ of them did so irregularly. Furthermore, although $50 \%$ of them said that they exercise, only $5.5 \%$ of them exercised regularly everyday [13]. Therefore, education and awareness studies have become more important in order for patients to be able to take an active role in successfully controlling and treating their DM. Although patient education is an integral component of diabetes care, deficiencies in the provision of health services for patients diagnosed with DM mean that patients are sometimes left to deal with their illness alone. Moreover, for the patients diagnosed with DM there is, unfortunately, not enough time given to patient trainings so that they can affect the needed changes in their lifestyle. Further complications and problems arise for patients in the rural areas of Turkey where the quality and the contacts for health services have decreased. Thus, the organization and structure of needed health services, especially primary care services, is as important in Turkey as it is in other developing countries.

In this study conducted in a province in eastern Turkey that prevalence of DM is higher than other region [4]. Plans were developed to make home visits to patients diagnosed with $\mathrm{DM}$ in order to restructure their daily-living activities and to improve their abilities to effectively cope with their disease. The activities patients need help with include the following: developing self-care and problem solving skills; improving ability of self-monitoring of blood glucose and blood pressure levels; improving foot-care techniques and healthy eating habits; help in maintaining ideal body weight; and ensuring a regular exercise routine. Home visits were also intended to teach patients how to cope with stress with the goal of decreasing DM related symptoms and thus contributing to a better prognosis $[11,14]$.

Modern diabetes care systems require integration and cooperation between health care teams [9]. The American Diabetes Association (2010) has stated that people with diabetes should receive medical care using a team approach. Such teams may include physicians, nurse practitioners, physician's assistants, nurses, dietitians, pharmacists, and mental health professionals with expertise and a special interest in diabetes [15]. Therefore, internal medicine nurse, nutritionist, physician, physiotherapist and public health nurse have all worked together on this study. In addition, further support related to physical exercise for diabetes patients was received from a physiotherapist. The purpose of this study is to evaluate the effectiveness of diabetes management program on diabetes control that performed by a health team.

\section{Hypothesis}

1. Blood glucose scores of the patients under the scope of intervention will increase a statistically significant degree according to the situation before intervention

2. Tensions scores of scores of the patients under the scope of intervention will increase a statistically significant degree according to the situation before intervention

3. Weight scores of the patients under the scope of intervention will increase a statistically significant degree according to the situation before intervention.

\section{Method}

Design: This study is a single-group pre-posttest design.

Setting: The study was conducted in Kars, a city situated in eastern Turkey.

Sample: Fifty-two (52) patients diagnosed with Type II Diabetes applied to the Internal Medicine Department of Kars State Hospital were included in this study. The sample size was calculated with post hoc power analysis. It was determined that 55 participants would give a power of $90 \%$ and $\alpha=0.05$ and blood glucose difference $=20$. Calculations were performed with only one group. Because the possibility existed that some of the patients could withdraw during the research, it was decided that the study should be conducted with 60 patients. However, at the end of the study the power of work was determined as $94 \%$ with $95 \%$ confidence interval and 0.05 error level. Potential patient participants were advised about the study through interviews, and at that time they were asked whether they wanted to participate or not.

\section{Sample inclusion criteria}

The study included individuals using the following criteria: participants had been diagnosed with Type 2 DM; they had no major physical or physiological disorder that would interfere with participation; they were able to see and hear well enough to participate; they could speak the Turkish language; they resided in the city center where the study was conducted; and they had consented to participate in the study. However, during the run-time of the study a total of 8 patients were withdrawn from research (2 patients thought the study was useless, 2 did not go to hospital for dietary instruction and 4 did not have their blood samples taken). Thus, the study was completed with 52 participants.

\section{Data collection}

The data of the study were collected by means of the Sociodemographic Characteristics Form, Assessment Form of the Disease Compliance of Diabetes Patients, and the Blood Glucose, Blood Pressure and Weight Tracking Chart. Although one of the best indicators of glycemic control is the level of HbA1c, it was not evaluated because HbAlc is not available in Kars.

The Assessment Form of the Disease Compliance of Diabetes 
Patients was formulated by researchers who had searched the literature $[3,10,12,16,17]$. This questionnaire consists of 33 questions evaluating DM patients' compliance to diet, exercise, and medical control.

\section{Study implementation}

The study was conducted through home visits to patients according to procedure given below;

First Stage (Determination of Suitable Patients): In this stage, we took Type 2 DM patients who had checked in or registered at the Kars State Hospital medical unit until we reached the desired sample size. During the interview in the policlinic the purpose of the study was explained to the patients and their home address and phone number were then taken.

Second stage (The Implementation of Home Visits and Patient Education): During the study, the researcher made a total of 9 home visits once each week. During these visits, the patients were given education about DM according to the restructured training booklet prepared by the researchers. For patients with DM this booklet contains information regarding the treatment, type, disease course, complications, assessment of DM, nutrition, exercise and the importance of using regular medications, monitoring blood glucose and blood pressure, and proper nutrition. Moreover, at this stage, a special diet had been designed for each patient by BÖ and the patients had been informed about it. The researchers had been given training about the importance of exercise for patients with DM and the exercises which can be recommended to patients. Due to the social, cultural, climatic and economic conditions of the Kars region and because so many female patients preferred exercises they could do at home, stretching-relaxation and overall body exercises were given more attention. For this purpose, an exercise programme was created for patients to be done at least three times per week for 30 minutes.

The patients were weighed dressed but without shoes. Height was measured without shoes, and blood pressure was measured with the patient in a sitting position. Blood pressure of the patients was measured from the left arm and calibration was measured with a manual sphygmomanometer. Before measuring, the patient was checked to be sure he/she was not tired. The blood glucose level was checked with glucose measuring devices at home. However, because home visits with patients could not be accomplished in the early hours of the morning, the evaluation of the fasting blood glucose level was not possible. Instead, the postprandial blood glucose was measured. Each visit with DM patients consisted of the following format:

1 Week: Meeting with the patient, giving information about the content of visits, the measurement of blood glucose/ blood pressure, implementation of the adaptation survey to Diabetes, taking blood and directing the patient to a dietician to create a special diet list.

2 Week: Taking blood for biochemical and enzymatic parameters from patients and regulating of nourishment in cooperation with a dietician.
3 Week: The measurement of blood glucose/blood pressure, the exercise training and planning (the importance of regular exercise, determination of exercises which can be done by patient and beginning of implementation of it), guiding the patients diagnosed with diseases such as cardio-vascular diseases, hernia, and asthma-COPD for exercises to a physiotherapist.

4 Week: The measurement of blood glucose /blood pressure, diabetes education (What is DM? What are the symptoms? How is it treated? How is the blood glucose meter used? Are diet lists being followed? Is the patient in compliance with these aspects of controlling his/her $\mathrm{DM}$ ?

5 Week: The measurement of blood glucose / blood pressure, nourishment in DM (the importance of blood glucose tracing and nourishment for regulating blood glucose, foods which can be consumed and not consumed, the amounts of nutrients in diet), looking over the diet list given by dietician and evaluating the patients' compliance.

6 Week: The measurement of blood glucose / blood pressure, DM education (the importance of blood glucose tracing, regular medicine usage, regular checkups, and a correct injection training for those using insulin injections).

7-8 Week: The measurement of blood glucose / blood pressure, prevention of complications of diabetes and the conditions under which a doctor should be consulted.

9 Week: Evaluating the home visits with patients and completion of the meeting.

Evaluation of the data: The data were evaluated with the SPSS program using numbers or percentages. After the intervention, the effectiveness of the intervention was evaluated using number, percentage, the one-sample t-test and McNemar.

Ethical Considerations: Participants were informed of the study's objective and were asked whether or not they would like to participate and written permission was taken.

\section{Results}

The age average of the patients was $60.96 \pm 9.83$ with $51.0 \%$ between the ages of $51-65$ years; $76.9 \%$ were women, $80.8 \%$ of them had primary school education or less, $96.2 \%$ of them had social security and $84.6 \%$ of them were living together with their wife/husband and children. In addition, $9.6 \%$ of them stated that their income was more than their expenses. The average BMI score of patients was $30.33 \pm 13.24$, and the BMI score of $68.2 \%$ of them was over 30 .

In checking the medicinal properties of these DM patients the average diagnosis duration was $8.15 \pm 6.78$ years; and it was determined that $53.8 \%$ of them had been diagnosed longer than five years ago; $59.6 \%$ of them had hypertension; $57.7 \%$ had hands and feet tingling; $36.5 \%$ had vision problems; $9.6 \%$ 
had impairment of renal function; and 9.6\% of them had foot ulcers. Insulin had been recommended for $46.2 \%$ of the patients, diet and exercises with insulin had been suggested for $48.0 \%$; and for $5.8 \%$ of patients only dietary treatment had been recommended.

The compliance levels in the pre and post intervention periods of the diabetes patients taking part in the study are shown in Table 1. When compared to the pre intervention period, the statistical analysis indicates that life-style changes, such as the frequency of controlling blood glucose, glycemic control, exercise compliance, increasing the amount of consumed vegetables and fruits, had significantly changed ( $p$ $<.05$ ) (Table 1).

When comparing results of our study both before and after the intervention, we can see that the patients' weight, blood pressure, and fasting blood glucose values had statistically and significantly changed (Table 2) (Figure 1).

\section{Hypothesis testing}

In summary, in terms of the hypotheses set out for the study, our results show that:

1. At the end of the study, a statistically significant difference was found between the first $(265.63 \pm 128.63)$ and last (215.48 \pm 69.71$)$ average scores of postprandial blood glucose of seniors receiving intervention $(\mathrm{t}=16.062, \mathrm{p}<0.05)$

2. A statistically significant difference was found between the first (139.75 \pm 17.53$)$ and last $(135.31 \pm 17.91)$ average scores of systolic blood pressure of elders receiving intervention $(\mathrm{t}=51.037, \mathrm{p}<0.05)$.

3. A statistically significant difference was found between the first $(86.28 \pm 13.50)$ and last $(80.40 \pm 23.13)$ average scores of the weight of elders receiving intervention $(\mathrm{t}=34.988, \mathrm{p}<0.05)$.

Table 1: The Patients'Compliance Level of Diabetes Before and After the Intervention.

The Frequency of Checking Blood Pre-intervention Post-intervention

\begin{tabular}{|c|c|c|c|c|c|}
\hline \multirow{2}{*}{$\begin{array}{l}\text { The Frequency of Checking Blood } \\
\text { glucose }\end{array}$} & & & \multirow{2}{*}{ Statistics } \\
\hline & $n$ & $\%$ & $n$ & $\%$ & \\
\hline $\begin{array}{l}\text { Once a week and more often } \\
\text { Once a month } \\
\text { He/she isn't controlled }\end{array}$ & $\begin{array}{l}14 \\
19 \\
19\end{array}$ & $\begin{array}{l}26.9 \\
36.5 \\
36.5\end{array}$ & $\begin{array}{c}38 \\
3 \\
11\end{array}$ & $\begin{array}{c}73.1 \\
5.8 \\
21.2\end{array}$ & $\begin{array}{l}14.400 \\
p=0.001\end{array}$ \\
\hline \multicolumn{6}{|l|}{ Glycemic control } \\
\hline $\begin{array}{l}\text { Under control } \\
\text { Irregular }\end{array}$ & $\begin{array}{l}28 \\
24\end{array}$ & $\begin{array}{l}53.8 \\
46.2\end{array}$ & $\begin{array}{l}36 \\
16\end{array}$ & $\begin{array}{l}69.2 \\
30.8\end{array}$ & $\begin{array}{l}3.561 \\
p=0.049\end{array}$ \\
\hline \multicolumn{6}{|l|}{ Doing exercises Status } \\
\hline $\begin{array}{l}\text { Being Done } \\
\text { Not being done }\end{array}$ & $\begin{array}{l}16 \\
36\end{array}$ & $\begin{array}{l}30.8 \\
69.2\end{array}$ & $\begin{array}{l}35 \\
17\end{array}$ & $\begin{array}{l}67.3 \\
32.7\end{array}$ & $\begin{array}{l}13.370 \\
p=0.001\end{array}$ \\
\hline \multicolumn{6}{|l|}{ The compliance status to diet } \\
\hline $\begin{array}{l}\text { Obeying v } \\
\text { Not obeying }\end{array}$ & $\begin{array}{l}27 \\
25\end{array}$ & $\begin{array}{l}51.9 \\
48.1\end{array}$ & $\begin{array}{l}36 \\
16\end{array}$ & $\begin{array}{l}69.2 \\
30.8\end{array}$ & $\begin{array}{l}3,240 \\
p=0.07\end{array}$ \\
\hline \multicolumn{6}{|l|}{$\begin{array}{l}\text { The amount of daily food } \\
\text { consumption }\end{array}$} \\
\hline $\begin{array}{l}\text { Less than } 3 \text { portion } \\
3 \text { portion and over }\end{array}$ & $\begin{array}{l}45 \\
7\end{array}$ & $\begin{array}{l}86.5 \\
13.5\end{array}$ & $\begin{array}{l}32 \\
20\end{array}$ & $\begin{array}{l}61.5 \\
38.5\end{array}$ & $\begin{array}{l}20,167 \\
p=0.001\end{array}$ \\
\hline
\end{tabular}

3 portion and over
Table 2: The Changes in The Patients' Some Blood Parameters Before and After the Intervention.

\begin{tabular}{|l|l|l|l|}
\hline & First Visit & Last Visit & Statistics \\
\cline { 2 - 4 } & Mean \pm SD & Mean \pm SD & \\
\hline Weight & $86.28 \pm 13.50$ & $80.40 \pm 23.13$ & $\mathrm{t}=34.988 \mathrm{p}=0.001$ \\
\hline Tension & & & \\
\hline Systolic Diastolic & $139.75 \pm 17.53$ & $135.31 \pm 17.91$ & $\mathrm{t}=51.037 \mathrm{p}=0.001$ \\
\hline Blood glucose (postprandial) & $265.14 \pm 10.94$ & $81.06 \pm 12.55$ & $\mathrm{t}=44,277 \mathrm{p}=0.001$ \\
\hline
\end{tabular}

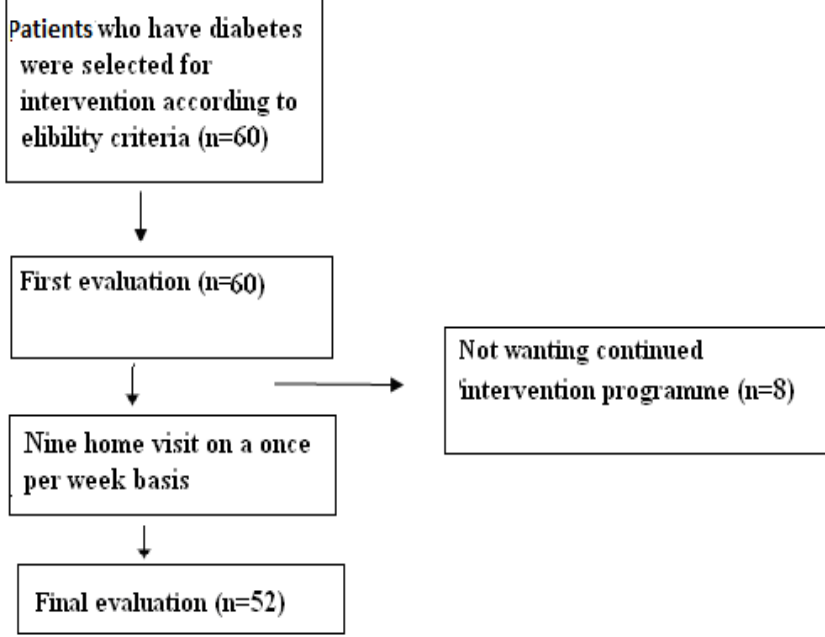

Figure 1: Participant Flow.

\section{Discussion}

Results of this study indicated that home-based diabetes management programme to control the effects of patients' DM had been effective. But, we have some limitations for this study included the lack of a control group, HbA1c levels were not evaluated and the study itself was of short duration.

Because DM is a chronic disease it requires active patient participation in self-care. IDF, ADA and most studies emphasize that assessment of self-management skills and the encouragement of continuous education on diabetes [18-21]. In many countries diabetes education is not an obligatory part of treatment, but it is regarded as contributing to improved quality of diabetes care. Some researchers have argued that knowledge acquisition does not translate into behavior change $[22,23]$.

DM treatment includes both pharmacological and nonpharmacological therapies. The present study promoted goal setting for glycemic control, blood pressure control, weight control and encouraged patients to change their behaviors through education and reinforcement using a home-visiting approach. Also, as in our study, the other study reports supported the effects on glycemic control and behavior as result of self-management training $[18,24,25]$. But we have some difficulties.

In this study, blood glucose must be evaluated before breakfast. But when we reached some patients' homes, they had 
already eaten something. Therefore, we evaluated their blood glucose levels postprandial. Another strengths of this study is that for the first time the patients received services related to their diabetes from a team consisting of a public health nurse, internal medicine nurse, dietitian, physiotherapist and physicians. For the purpose of training and counseling, the patients were visited at home, and they were encouraged in efforts to increase their motivation in managing their DM. At the end of the study, it was determined that patients postprandial blood glucose levels had decreased significantly.

Hypertension is a common comorbidity of diabetes that affects the majority of patients with prevalence depending on type of diabetes, age, obesity, and ethnicity. Hypertension is also a major risk factor for both cardiovascular diseases and microvascular complications [15]. Furthermore, dyslipidaemia contributes significantly to atherosclerotic disease and hypertension in patients with DM. Our study showed that systolic and diastolic blood pressure make a significant difference. Similar to our study, though different results were obtained in the meta-analysis done by Wens et al. and Vermeire et al., results showed that the patients' systolic blood pressure decreased significantly after the intervention $[26,27]$. In a study done by Dejesus et al., there was not a significant change in diastolic and systolic blood pressure [28]. New et al., evaluated the effect of a nurse-led intervention to treat and control hypertension and hyperlipidemia and found that the utilization of nurse specialists was an extremely effective approach to assist patients in reducing their hyperlipidemia and achieving improved blood pressure control [29].

Kars is located at a high-altitude and has very harsh climatic conditions. The main source of livelihood of a large proportion of the population is stockbreeding. Moreover, consumption of salted goose, meat consumption, fat and salt cheese consumption and saturated fat consumption (yellow oil) are rather high, while consumption of fruit and vegetables is limited. In this study, It was seen that compliance the diet and amount of consumed vegetables and fruits were increased. In this study although we have not evaluated the lipid profile, our study is important in terms of coronary heart risk reduction. Moreover, other studies have indicated that coronary heart risk can be reduced with diet changes given to diabetes patients [15]. Schwedes et al., who conducted meal-related, structured self-monitoring of blood glucose levels to improve diabetic control, were able to achieve decreased coronary heart risk in their patients [30]. The study of Wattana et al., noted that at the end of a diabetes self-management programme, there was a reduction in the patients' coronary heart risk in favor of the experimental group [25].

In this study, home-based diabetes management program is effective in helping DM patients reduce their body weight. Though various studies have obtained different results, our study, while of short duration, showed that a statistically significant difference in the patients' weight had occurred. The study of MacMahon Tone et al., and Houweling et al., found that a change in weight had not occurred at the end of study $[24,31]$. McTigue et al., indicated that the patients' weight in the intervention group had significantly changed at the end study of a lifestyle curriculum of a 12-week session, group-based version of the Diabetes Prevention Programme [32]. Because Kars has a harsh climate, the inhabitants spend most of their time at home and with their daily work. For exercise, their environmental and field opportunities are quite limited. At the same time, levels of exercise throughout the entire country of Turkey are inadequate. Because of this, in this study, indoor exercises was planned and implemented. Exercise and diet affect the weight considerably, and the actions or behaviors of DM patients certainly can influence these factors. To assist patients, the dietitian plays a pivotal role in counseling patients on diet modification and in designing a diet for patients based on their preferences and health status.

\section{Conclusion}

Our study has shown that monitoring DM patients at home has increased the levels of compliance of the patients to making improvements in their health, and it has affected parameters such as weight, blood pressure and postprandial blood glucose in a positive way. Results of our study show that particularly in rural areas such as Kars, where health services are limited, it is clear that primary care services are greatly needed. Future services for DM patients should be headed by a multidisciplinary team, education clinics for diabetes patients should be established in hospitals, and the nurses should play a very active role.

\section{Acknowledgement}

The authors thanks to the women who attended the study.

\section{Work in progress}

This study has shown that monitoring DM patients at home has increased the levels of compliance of the patients to making improvements in their health.

Integration and cooperation between health care teams is very important for effective diabetes managment

In Rural area, home based nursing and intervetion has critical importance specially for disavantaged peoples with diabetes.

\section{References}

1. Booth GL, Kapral MK, Fung K, Tu JV (2006) Recent Trends in Cardiovascula Complications among Men and Women With and Without Diabetes. Diabetes Care 9: 32-37. Link: https://goo.gl/al3x71

2. Watanabe M, Yamaoka K, Yokotsuka M, Tango T (2003) Randomized Controlled Trial of a New Dietary Education Program to Prevent Type 2 Diabetes in a High -Risk Group of Japanese Male Workers. Diabetes Care 26 3209-3214. Link: https://goo.gl/KTZfgg

3. Kara B (2006) Relationship between Anxiety and metabolic control in Type 2 Diabetes Mellitus patients. Community and Health 16: 36-40.

4. Satman I (2010) Türkiye Diyabet Epidemiyoloji (TURDEP II) Çalışması Genel Sonuçları (20 yaş üstü). [General Outcomes of Turkey Diabetes Epidemiology Study (TURDES)(Over 20 years)] 32. Türkiye Endokrinoloji ve Metabolizma Hastalıkları Kongresi [Congress of Endocrinology and Methabolizm of Turkey], TURDEP Paneli, 13-17 Ekim, Antalya, Kongre Kitabı. 2010. 
5. Armstrong DG, Lavery LA, Quebedeaux TL, Walker SC (1997) Surgical morbidity and the risk of amputation due to infected puncture wounds in diabetic versus nondiabetic adults. J Am Podiatr Med Assoc 87: 321-326. Link: https://goo.gl/v5uaYV

6. Durna Z (2010) Diyabetin Sınıflandırılması ve Tanı Kriterleri (Classification of Diabetes and Diagnosis Criterion). Link: https://goo.gl/8wvuZo

7. Diabetes Control and Complications Trial Research Group (1993) The effect of intensive treatment of diabetes on the development and progresion of long trem complications in insülin dependent diabetes mellitus. N Engl J Med 329 977-986. Link: https://goo.gl/1 mvfK

8. Ișıldak M, Gürlek A (2006) Mikrovascular protection in A. Diabetes Mellitus Türk J Cardiol 9: 22-27.

9. International Diabetes Federation (IDF) (2012) International Standards for Diabetes Education. Link: https://goo.gl/VvDGxg

10. Hannah JB, Alberts J (2005) Motivators and Barriers to Attending a Diabetes Education Class and Its Impact on Beliefs, Behaviors, and Control over Diabetes. Geriatric Nursing 26: 50-58. Link: https://goo.gl/ECsESW

11. Sinclair AJ, Paolisso G, Castro M, Gadsby R, Mañas LR (2011) European Diabetes Working Party for Older People 2011 Clinical Guidelines for Type 2 Diabetes Mellitus. Executive Summary. Diabetes Metabolizm 37: S27-38. Link: https://goo.gl/CvzKJf

12. Gökdoğan F, Akıncı F (2001) The implementation About Perceptions of Health and Disease of diabetics living in Bolu. CU Institutional Journal of Nursing 5: 10-17.

13. Kartal A, Çağırgan MG, Tığlı H (2008) The attitudes aimed to Care and Treatment of Patients with Type 2 Diabetes and the factors affecting the attitude. TAF Preventive Medicine Bulletin 7: 223-230.

14. Buzlu S (2002) Psychosocial aspects of diabetes. Erdogan S (ed), Diabetes Nursing Basic Sciences, Istanbul: Yüce Publications Distribution.

15. American Diabetes Association (ADA) (2010) Standards of Medical Care in Diabetes. Diabetes Care 33: 11-61. Link: https://goo.gl/rHikvY

16. Duke SA, Colagiuri S, Colagiuri R (2009) Individual patient education for people with type 2 diabetes mellitus. Cochrane Database Syst Rev 21 CD005268. Link: https://goo.gl/6gYGnc

17. Miller CK, Edwards L, Kissling G, Sanville L (2002) Nutrition education improves metabolic outcomes among older adults with diabetes mellitus: results from a randomized controlled trial. Prev Med 34: 252-259. Link: https://goo.gl/4JK5Fs

18. Norris SL, Lau J, Smith SJ, Schmid CH, Engelgau MM (2002) Self-management education for adults with type 2 diabetes: a meta-analysis of the effect on glycemic control. Diabetes Care 25: 1159-1171. Link: https://goo.gl/0q2ozr

19. Singh N, Armstrong DG, Lipsky BA (2005) Preventing foot ulcers in patients with diabetes. JAMA 293: 217-228. Link: https://goo.gl/p9d0rG

20. Strine TW, Okoro CA, Chapman DP, Beckles GL, Balluz L, et al. (2005) The impact of formal diabetes education on the preventive health practices and behaviors of persons with type 2 diabetes. Prev Med 41: 79-84. Link: https://goo.gl/iej2vc

21. Tien KJ, Hung HC, Hsiao JY, Hsu SC, Hsin SC, Shin SJ, et al. (2008) Effectiveness of comprehensive diabetes care program in Taiwanese with type 2 diabetes. Diabetes Res Clin Pract 79: 276-283. Link: https://goo.gl/NkMyLc

22. Krichbaum K, Aarestad V, Buethe M (2003) Exploring the connection between self-efficacy and effective diabetes self-management. Diabetes Educ 29: 653662. Link: https://goo.gl/DSLQJo

23. Snoek F, Visser A (2003) Improving quality of life in diabetes: how effective is education? Patient Educ Couns 51: 1-3. Link: https://goo.gl/cxFzKz

24. MacMahon Tone J, Agha A, Sherlock M, Finucane F, Tormey W, et al. (2009) An intensive nurse-led, multi-interventional clinic is more successful in achieving vascular risk reduction targets than standard diabetes care. Ir J Med Sci 178: 179-186. Link: https://goo.gl/BLdwMh

25. Wattana C, Srisuphan W, Pothiban L, Upchurch SL (2007) Effects of a diabetes self-management program on glycemic control, coronary heart disease risk, and quality of life among Thai patients with type 2 diabetes. Nurs Health Sci 9: 135-141. Link: https://goo.gl/lacAmC

26. Wens J, Vermeire E, Hearnshaw H, Lindenmeyer A, Biot $Y$, et al. (2008) Educational interventions aiming at improving adherence to treatment recommendations in type 2 diabetes: A sub-analysis of a systematic review of randomized controlled trials. Diabetes Res Clin Pract 79: 377-388. Link: https://goo.gl/iw00cX

27. Vermeire $E$, Wens $J$, Van Royen $P$, Biot $Y$, Hearnshaw $H$, et al. (2005) Interventions for improving adherence to treatment recommendations in people with type 2 diabetes mellitus. Cochrane Database Syst Rev 18 CD003638. Link: https://goo.gl/na2z1t

28. Dejesus RS, Chaudhry R, Leutink DJ, Hinton MA, Cha SS, et al. (2009) Effects of efforts to intensify management on blood pressure control among patients with type 2 diabetes mellitus and hypertension: a pilot study. Health Risk Manag 5: 705-711. Link: https://goo.gl/BabtWz

29. New JP, Mason JM, Freemantle N, Teasdale S, Wong LM, et al. (2003) Specialist nurse-led intervention to treat and control hypertension and hyperlipidemia in diabetes (SPLINT): a randomized controlled trial. Diabetes Care 26: 2250-2255. Link: https://goo.gl/9B7bYI

30. Schwedes U, Siebolds M, Mertes G. SMBG Study Group (2002) Meal-related structured self-monitoring of blood glucose: effect on diabetes control in non-insulin-treated type 2 diabetic patients. Diabetes Care 25: 1928-1932. Link: https://goo.gl/ZTvn8k

31. Houweling ST, Kleefstra N, van Hateren KJ, Kooy A, Groenier KH, et al. (2009) Diabetes specialist nurse as main care provider for patients with type 2 diabetes. Neth J Med 67: 279-284. Link: https://goo.gl/i1 Wmox

32. McTigue KM, Conroy MB, Bigi L, Murphy C, McNeil M (2009) Weight loss through living well: translating an effective lifestyle intervention into clinical practice. Diabetes Educ 35: 199-204. Link: https://goo.gl/fznQk0

Copyright: (C) 2016 Karatay G, et al. This is an open-access article distributed under the terms of the Creative Commons Attribution License, which permits unrestricted use, distribution, and r eproduction in any medium, provided the original author and source are credited. 